\title{
EVALUACIÓN DEL IMPACTO PAISAJISTICO PRODUCIDO POR LAS ACEQUIAS DE RIEGO Y LOS DEPÓSITOS PARA ABASTECIMIENTO DE AGUA MEDIANTE EL USO DE TÉCNICAS DE SIMULACIÓN
}

\author{
(EVALUATION OF THE IMPACT ON LANDSCAPE OF IRRIGATION CANALS AND \\ WATER-SUPPLY TANKS, USING SIMULATION TECHNIQUES) \\ Juan Ortiz Sanz, Teresa Teijeiro Rodríguez y Ma Jesús Fanjul Alonso \\ Ingenieros Agrónomos-Escuela Politécnica Superior. Univ. de Santiago de Compostela
}

ESPAÑA

Fecha de recepción: 6-X-95

$113-38$

\section{RESUMEN}

El impacto visual producido en el paisaje por las estructuras hidráulicas, tanto longitudinales como puntuales, es un aspecto que rara vez se considera en su diseño. Tomando como muestra de estudio algunas de las acequias de riego y los depósitos para abastecimiento de agua en el Páramo de León, se analiza en el presente artículo el efecto visual de este tipo de construcciones. En cuanto a las primeras, parece que suponen un impacto muy reducido, sobre todo cuando el paisaje se encuentra degradado. Las consecuencias son mucho más claras en el caso de los segundos, máxime cuando se opta por tipologias y materiales poco compatibles con el paisaje.

\section{SUMMARY}

The visual impact of hidraulic structures, both longitudinal and puntual, on the landscape is an aspect which is not generally regarded on their design. In this paper the visual effect of this kind of constructions will be analized, having as subject of study some irrigation canals and tanks for municipal water suply. As for the former, it seems they cause a very small impact, specially when the landscape is degraded. Consequences are much more perceptible in the later, particulary if typologies and materials incompatible with the landscape are chosen.

\section{Introducción}

Existen algunos trabajos que analizan la evaluación del impacto visual de infraestructuras de gran magnitud, como carreteras (1) (2) (3) (4) o grandes presas (5) (6), sin embargo, a la hora de proyectar una obra hidráulica de pequeña envergadura, generalmente no se consideran las consecuencias que ésta pueda tener en el entorno visual de su emplazamiento. Es de señalar que proyectos de este tipo, tanto de carácter puntual como longitudinal, pueden tener importantes repercusiones en el paisaje de determinadas zonas rurales.
El Páramo de León, por sus especiales características topográficas, es una de esas zonas en las que el manejo y distribución del agua, tanto para riego como para abastecimiento de la población, requiere del diseño y ejecución de infraestructuras hidráulicas, tales como depósitos y acequias, que se deben elevar sobre el terreno, lo que les hace ser muy llamativas.

Respecto a los primeros, los núcleos rurales del Páramo en raras ocasiones disponen de puntos cercanos al pueblo con la suficiente altitud como para acoger un depósito de abastecimiento de agua por gravedad y que ésta llegue al 
usuario en buenas condiciones de presión. Por este motivo, en la mayoría de los casos, se tuvieron que diseñar depósitos elevados, de una altura y proporciones tales que representan un hito muy notable en el entorno visual de la población. En un principio se construyeron generalmente a base de fábrica de ladrillo, pero el crecimiento de la población, el desarrollo de nuevos materiales (fundamentalmente el hormigón armado) y la diferencia creciente entre el coste de las técnicas de construcción antiguas y las modernas, motivaron la proliferación de depósitos de materiales y tipologías diferentes, más baratos y de mayor capacidad, pero visualmente más agresivos.

En cuanto a las acequias, la zona se pobló de ellas a mediados de siglo, cuando se realizó el Plan de regadío del embalse de Barrios de Luna, lo que supuso un fuerte cambio en el paisaje del Páramo. La vasta zona con predominio del cultivo de cereal en secano, dejó paso a un mosaico de aprovechamientos diferentes, tanto agrícolas (maíz, remolacha, etc.) como forestales (fundamentalmente choperas), de características visuales diferentes al dominante en la época anterior. Para abastecer agua a todas las parcelas incluidas en el plan, fue necesario construir numerosas acequias, que representan una importante fuente de impactos visuales para el territorio que surcan.

\section{Planteamiento del trabajo}

Existen varios métodos y estudios para la evaluación de impacto de las instalaciones sobre el paisaje (7) (8)(9) (10) (11) (12). En este trabajo nos centramos en las técnicas de simulación de imágenes, que valoramos con encuestas realizadas al público. Los materiales y la metodología empleada es sumamente sencilla, estando al alcance de cualquier profesional. Utilizamos un Ordenador Compatible con procesador 486 , un programa de retoque fotográfico, scanner e impresora por sublimación. En cualquier caso, si no se dispusiera de estos dos últimos elementos, se pueden encargar estos servicios a empresas especializadas, lo que supone un coste adicional aproximado de 900 pts/foto.

Para el estudio que pretendíamos llevar a cabo, era necesario reconocer la zona y tomar fotografias de los depósitos y las acequias que hay en ella. Esto se hizo durante el verano de 1995, utilizando para ello una cámara de $35 \mathrm{~mm}$ y película 100 ASA. Se fotografiaron todos aquellos depósitos y acequias que a priori parecían más llamativos, lo que supuso un total de aproximadamente 50 imágenes.

Una vezestudiadas las anteriores tomas, escogimos aquellas que nos podían resultar más útiles para llevar a cabo la valoración del impacto paisajístico producido por este tipo de obras. Así, se seleccionaron 5 fotografias: 2 de depósitos y 3 de acequias. A continuación, utilizando técnicas de simulación y tratamiento informatizado de imágenes, realizamos dos tipos de modificaciones en las fotografias: a) A cada una de las 5 imágenes seleccionadas, se les hizo "desaparecer" el motivo de estudio.

b) En una de las fotografías de depósitos tratadas anteriormente, se "pegó" uno diferente al "original", con lo cual disponíamos de tres tomas desde este punto de vista:

- Sin depósito

- Con el depósito "original"

- Con un depósito "importado"

Las 5 imágenes seleccionadas fueron digitalizadas y modificadas con ayuda del programa Adobe Photoshop, para posteriormente filmar y pasar a papel todas ellas -tratadas y sin tratar-, con el objeto de evitar que las diferencias en la calidad final de las fotografias que queríamos comparar, pudiera influir en los resultados.

Las 11 fotografias ( 5 originales y 6 tratadas) se mezclaron e incluyeron en una colección de un total de 48 imágenes, colocando en posiciones alejadas cada pareja tratadasin tratar, de forma que, al realizar las encuestas, la persona preguntada no recordara o asociara ambas imágenes.

Tras confeccionar 12 cartulinas A4 con 4 fotografias tamaño 9x13 cada una, se realizaron encuestas individualizadas a 100 personas, a las que se pidió que incluyera cada una de las 48 imágenes en una de las siguientes categorías: Muy mala -1 Punto-, Mala -2 Puntos-, Regular -3 Puntos- , Buena -4 Puntos- y Muy buena -5 Puntos-

Una vez hecho esto, se transformaron las puntuaciones medias obtenidas por cada fotografía a valores comprendidos entre 0 y 100 puntos y se compararon las puntuaciones otorgadas a cada una de las 6 fotografias tratadas con la de sus respectivos originales.

\section{Resultados}

En las Tablas №s 1 y 2 se presentan los resultados obtenidos tras el estudio. La Tabla $\mathrm{N}^{0} 1$ refleja las puntuaciones del primer tratamiento -con elemento y sin elemento-, y la Tabla $N^{\circ} 2$ los valores otorgados por los encuestados al mismo paisaje sin elemento, con el elemento "original" (depósito de hormigón) y con el "importado" (depósito de ladrillo y teja).

Se pasa a continuación a analizar por tipo de construcción y con detalle estos resultados, mostrando las fotografias utilizadas en las encuestas.

\section{Impacto paisajístico de las acequias para riego}

En el primer caso, vemos cómo la presencia en un paisaje de una acequia de riego fabricada en hormigón (Fotografia $N^{\circ} 1$ ), hace que la valoración de éste sea casi 10 Puntos más baja que en el caso del mismo paisaje sin dicha estructura 
TABLA 1

Resultados del primer tratamiento

\begin{tabular}{|c||c|c||c|c|c||}
\hline \hline \multirow{2}{*}{ MOTIVO } & \multicolumn{2}{|c|}{ CON ELEMENTO } & \multicolumn{2}{|c|}{ SIN ELEMENTO } & \multirow{2}{*}{ DIFERENCIA } \\
\cline { 2 - 5 } & FOTO & PUNTOS & FOTO & PUNTOS & \\
\hline \hline Acequia & 1 & 43 & 2 & 52,25 & $-9,25$ \\
\hline Acequia & 3 & 42,5 & 4 & 50,25 & $-7,75$ \\
\hline Acequia & 5 & 26,25 & 6 & 27 & $-0,75$ \\
\hline Depósito & 7 & 25,75 & 8 & 49 & $-23,25$ \\
\hline
\end{tabular}

TABLA 2

Resultados del segundo tratamiento

\begin{tabular}{|c|c|c|c|c|c|c|}
\hline \multirow[t]{2}{*}{ MOTIVO } & \multicolumn{2}{|c|}{ DEPÓSITO } & \multicolumn{2}{|c|}{$\begin{array}{c}\text { DEPÓSITO } \\
\text { HORMIGÓN } \\
\text { ("ORIGINAL") }\end{array}$} & \multicolumn{2}{|c|}{$\begin{array}{c}\text { DEPÓSITO } \\
\text { LADRILLO } \\
\text { ("IMPORTADO") }\end{array}$} \\
\hline & FOTO & PUNTOS & FOTO & PUNTOS & FOTO & PUNTOS \\
\hline Depósito & 9 & 44,5 & 10 & 29,25 & 11 & 42 \\
\hline \multicolumn{3}{|c|}{ DIFERENCIA CON ELEMENTO-SIN ELEMENTO } & \multicolumn{2}{|c|}{$-15,25$} & \multicolumn{2}{|c|}{$-2,5$} \\
\hline
\end{tabular}

(Fotografía 2). De igual forma, entre los paisajes de las Fotografías №s 3 y 4 , se obtuvieron diferencias similares (7,5 Ptos.). Sin embargo, en las imágenes №s 5 y 6 , apenas hay diferencias en la valoración obtenida por cada uno de los dos paisajes (0,75 Ptos.).

A la vista de los resultados obtenidos, se puede observar como las diferencias entre las fotografías de las dos primeras

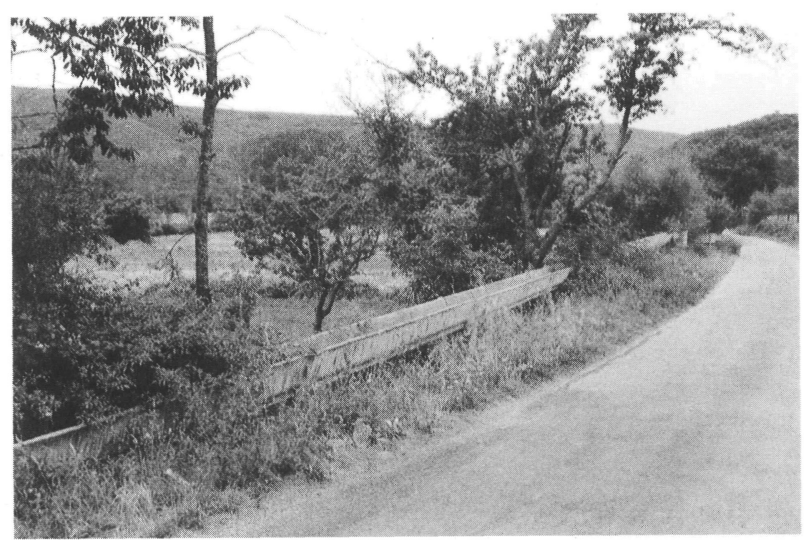

Foto 1.- Paisaje original que muestra una acequia a base de hormigón. Fue calificado por el público como Regular (43 Ptos.).

(c) Consejo Superior de Investigaciones Científicas Licencia Creative Commons 3.0 España (by-nc) parejas $(9,75$ y 7,5 Ptos.) son mucho mayores que las de la tercera $(0,75$ Ptos. $)$. Esto se podría deber a la presencia en el primer término de las Fotografias №s 5 y 6 , de una caseta de riego con un acabado precario, que hace que el entorno visual esté caracterizado por algunas modificaciones antrópicas, con lo cual, la existencia o no de la obra hidráulica apenas produciría efecto alguno en el paisaje

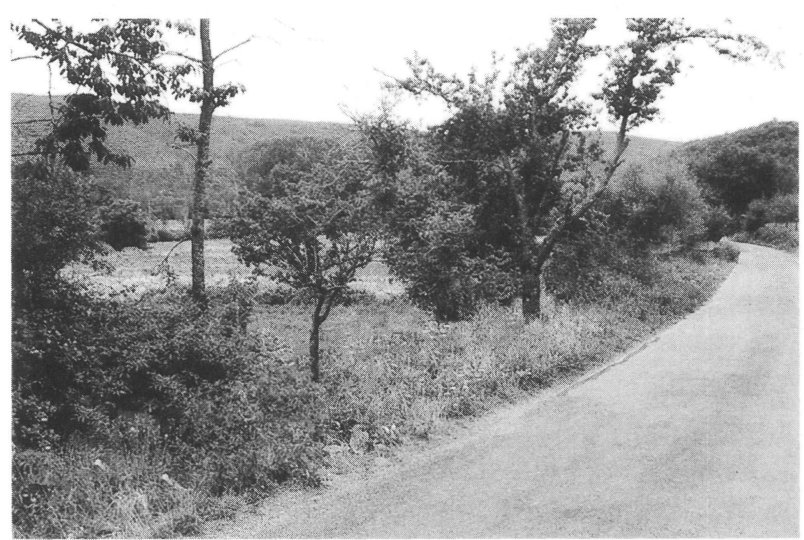

Foto 2.- Paisaje en el que se ha hecho desaparecer la acequia que presentaba originalmente (Foto 1). La catalogación volvió a ser como Regular (52,25 Ptos.). 


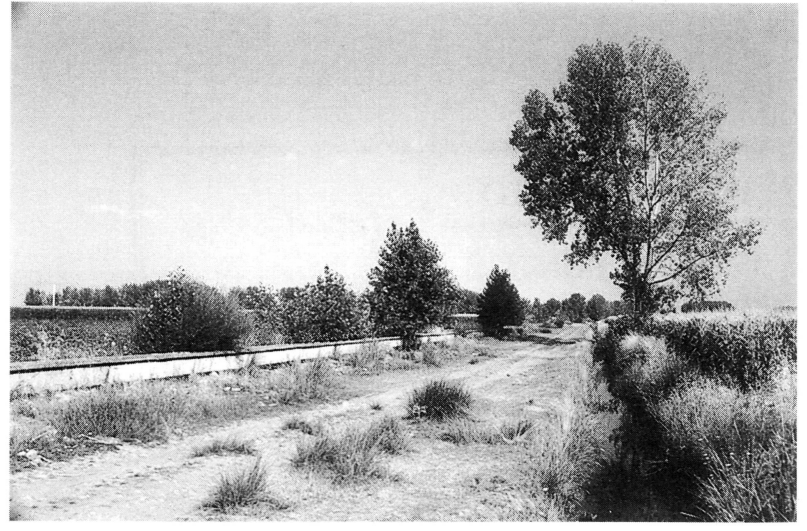

Foto 3.- Paisaje catalogado por el público como Regular (42,5 Ptos.).

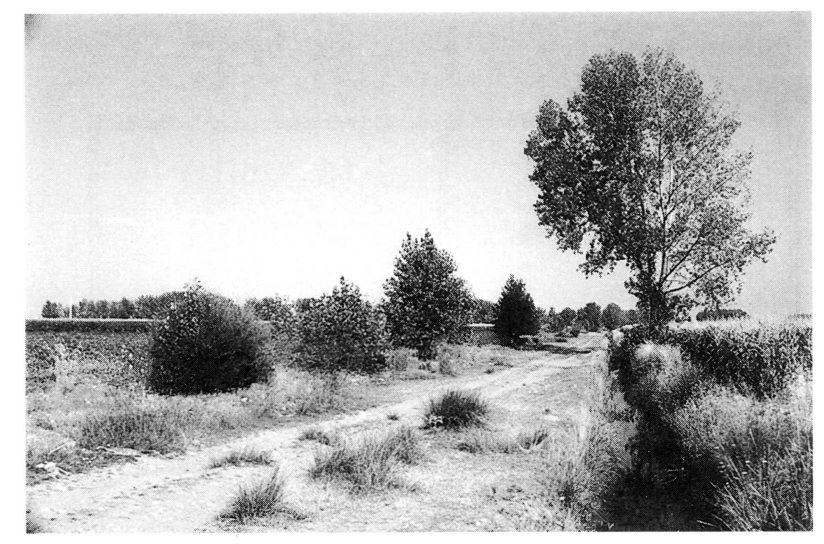

Foto 4.- Tras el tratamiento informático de la imagen de la foto 3 (original con elemento), la valoración hecha por los encuestados ascendió 7,75 Puntos.

\section{Impacto paisajístico de los depósitos para abastecimiento municipal de agua}

La Fotografía $N^{0} 7$, muestra el depósito de abastecimiento municipal de agua de una localidad del Páramo que hubo de ser ampliado. Se trata de una construcción situada en un lugar muy llamativo, en concreto, de la ampliación de un antiguo depósito troncopiramidal para la que se recurrió a uno cilíndrico de poliester, elevado mediante cuatro pilares de hormigón. La gran diferencia (23,25 Ptos.) entre las puntuaciones otorgadas a este paisaje (Sin elemento; Categoría Regular: 49 Ptos.) y al original (Fotografía $N^{\circ} 8$; Con elemento; Categoría Malo: 25,75 Ptos.), prácticamente el doble el primero que el segundo, se puede deber fundamentalmente a tres causas:

- Su localización y dimensiones del nuevo depósito, hacen que interrumpa de manera muy clara y pronunciada la línea del horizonte.

- Su tipología constructiva no es la más adecuada.

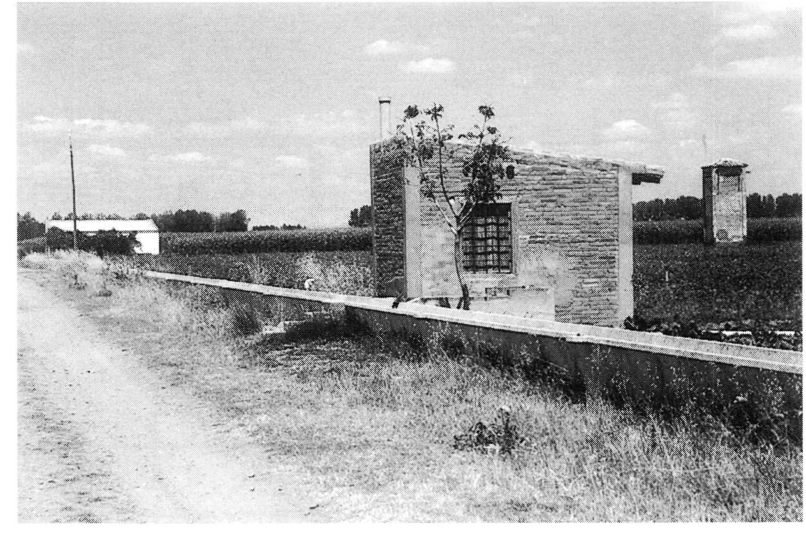

Foto 5.- Paisaje con acequia que fue calificado por el público como Malo (26,25 Ptos.).

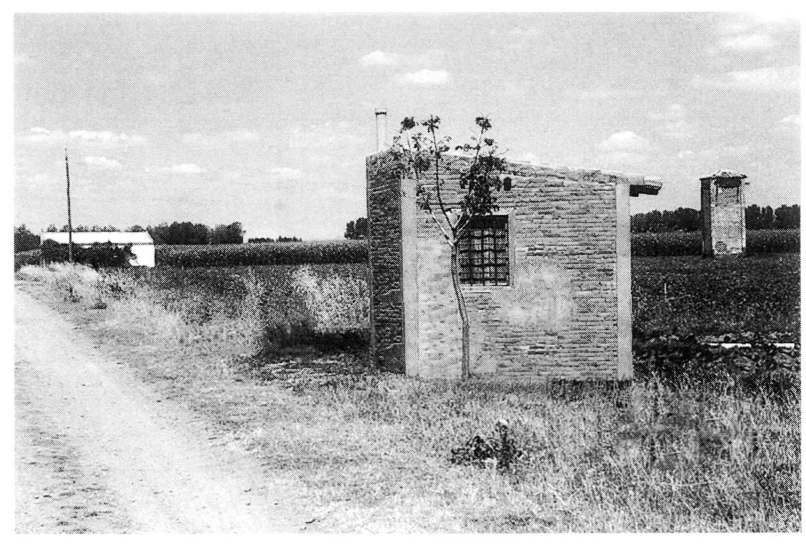

Foto6.-Porla diferencia de puntuación otorgada a estaimagen modificada (27 Ptos.) conla original (Foto 5), determinamos el reducido impacto que causa la acequia que lo recorre (0,75 Ptos.).

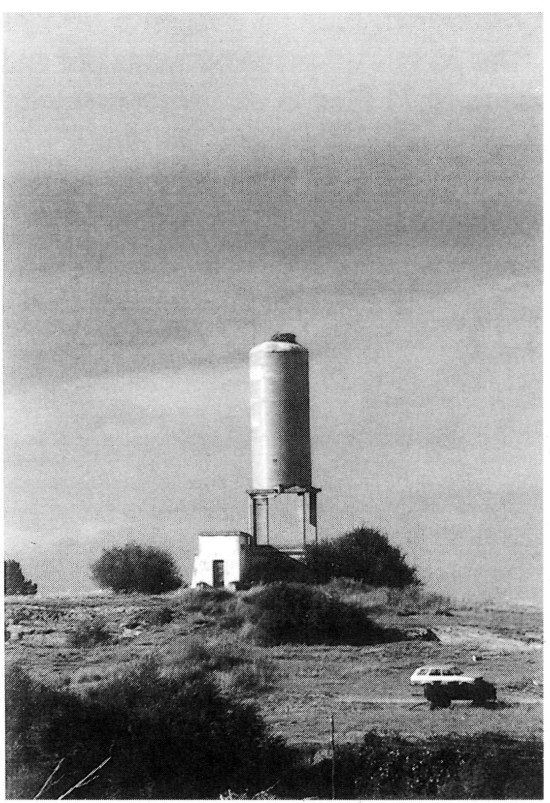

Foto 7.-Paisaje original, con depósito de poliester sobre pilares de hormigón. fue catalogado como malo (25,75 Ptos.). 


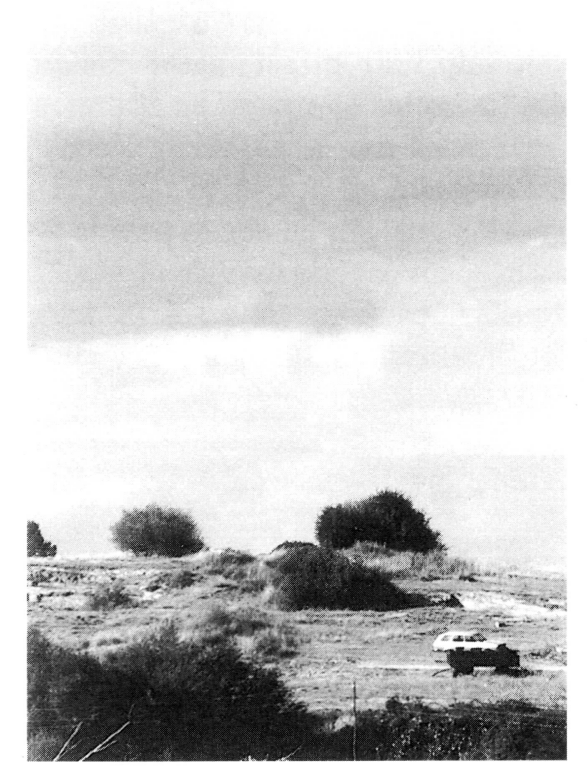

Foto 8.- La imagen tratada muestra el paisaje original (Foto 7) en el que se ha eliminado el depósito. El público estimó que era un paisaje regular (49 Ptos.).

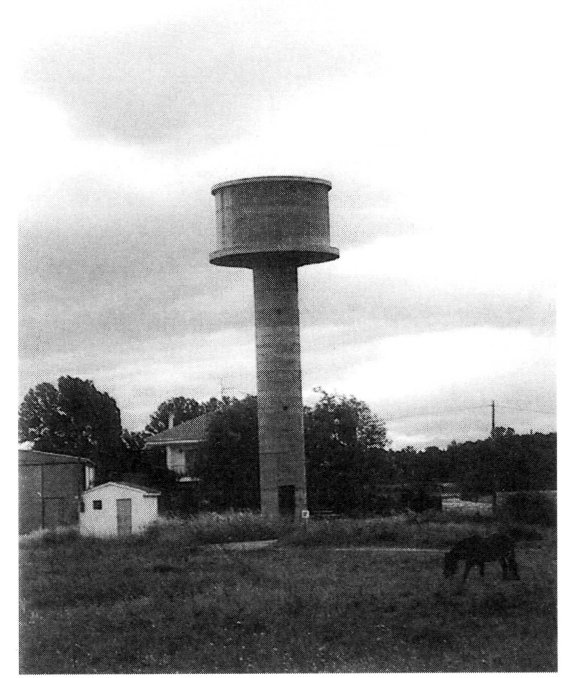

Foto 10.- Paisaje original en el que aparece un depósito para abastecimiento de agua a base de hormigón. La puntuación otorgada porel público fue de 29,25 Puntos.

- Los materiales empleados para su construcción, son de un color y una textura poco acordes con el entorno.

Respecto a las Fotografías $\mathrm{N} \cong$ 9, 10 y 11, el análisis de las puntuaciones obtenidas por cada una de ellas revela que, sin el elemento, el paisaje se calificaría como Regular $(44,5$

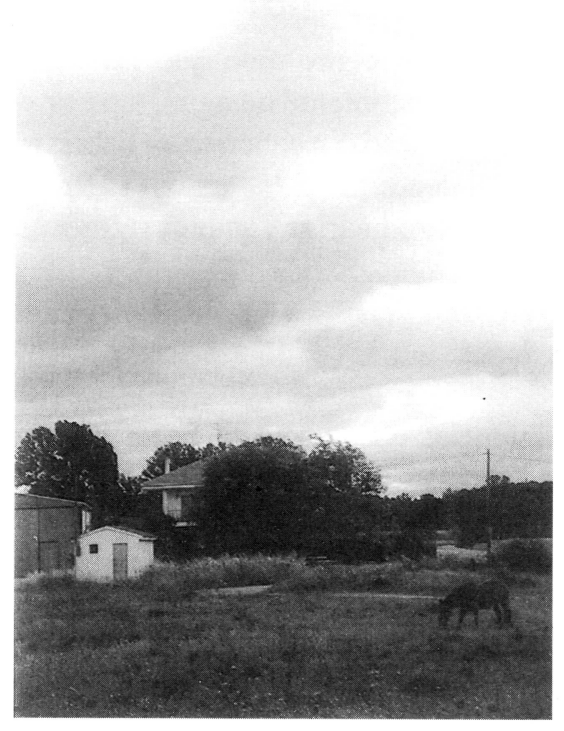

Foto 9.- Primera imagen de una serie de tres (Fotos 9, 10 y 11). Esta es el resultado de eliminar. el depósito que originalmente presentaba. (Obtuvo 44,5 Puntos.

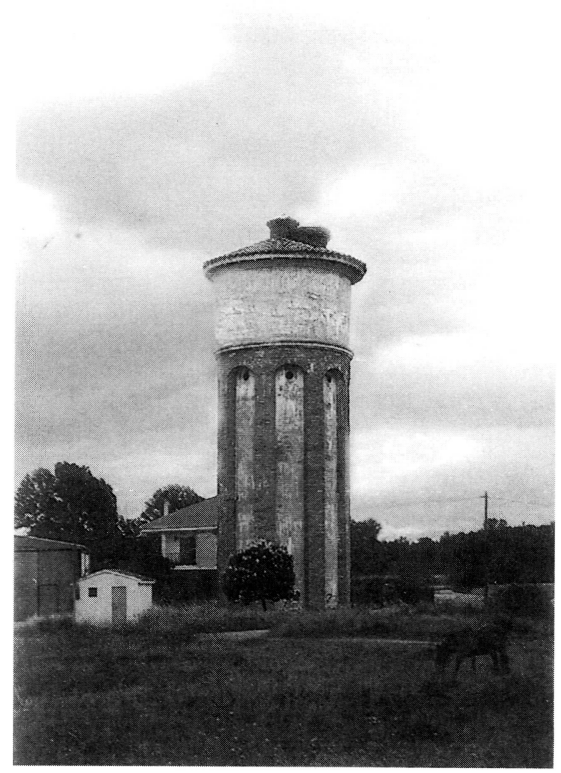

Foto 11.- En esta imagen se "pegó" un depósito a base de ladrillo y teja, diferente del original (Foto 11). Su puntuación fue de 42 Puntos. 
elevada que la diferencia entre las Fotografías №s 9 Y 11 (2,5 Puntos). Se puede ver cómo la correcta elección de la tipología y materiales de construcción hubiera minimizado el impacto paisajístico negativo que genera el depósito elevado de abastecimiento de agua, a pesar de ser este último más voluminoso. En concreto, se habría reducido el efecto visual del depósito 12,75 Puntos $(15,25-2,5)$, lo que supone que no se producirían cambios significativos en la calidad del paisaje.

\section{Conclusiones}

1.- Las diferencias observadas al hacer desaparecer del paisaje las acequias, parecen poner de manifiesto que la presencia de este tipo de estructuras hidráulicas longitudinales no impactan de manera muy negativa a la escena, sobre todo cuando ésta está degradada. Sería necesario evaluar el efecto que sobre el paisaje produce la vegetación que llevan asociada, para determinar las posibilidades de este tipo de infraestructuras como elementos mejoradores del medio.

2.- Parece mucho más claro el efecto negativo que sobre el entorno visual causan los depósitos para el abastecimiento de agua, aunque éste se podría minimizar mediante tipologías adecuadas y el empleo de materiales más compatibles con el paisaje, como la utilización de ladrillo en lugar de hormigón.
3.- El programa Adobe Photoshop se muestra muy útil, por la sencillez en el manejo de las imágenes, siendo posible también imprimir directamente las fotografías digitalizadas (todas las mostradas en el presente artículo fueron realizadas con la impresora Kodak XL7700, excepto la Fotografía $N^{0} 1$, que se trata del original). Podemos concluir que, hoy en día, es posible disponer de materiales y métodos para las técnicas de simulación a un precio razonable, en pocos minutos (4 fotografías de $9 \times 13 \mathrm{~cm}$ se imprimen en 10 minutos) y con una gran calidad.

\section{Agradecimientos}

Los autores agradecen el asesoramiento prestado por el Dr. Ignacio Cañas Guerrero en el planteamiento de la metodología y la corrección de las pruebas efectuadas para la elaboración del presente artículo, así como a la Comisión Interministerial de Ciencia y Tecnología del Ministerio de Educación y Ciencia, pues el presente trabajo ha sido elaborado gracias a la financiación otorgada a los proyectos de investigación "Evaluación del impacto visual producido por las construcciones agrarias. Caso particular de la Arquitectura del Barro" (CICYT PB 93-0199) y "Estudio de los métodos de valoración de los recursos visuales producido por las construcciones en el ecosistema rural. Estimación del impacto producido por las nuevas construcciones" (CICYT NAT 90-0099).

\section{BIBLIOGRAFÍA}

(1) USDOT: Visual impact assessment for highway projects. Federal Highway Administration Office of Environmental Policy. Washington. 1981.

(2) MCHARG, I.: Where should highways go? Landscape Architecture. 57. 1967. Págs. 179-181.

(3) CLAMP, P.: A study in the evaluation of landscape and the impact of roads. Landscape Research. 1(11). 1975. Págs. 6-7.

(4) CAÑAS GUERRERO, I.: Estimación del impactopaisajístico de las carreteras Informes de la Construcción. Vol. 44-N 425-426, mayo/junio-julio/agosto 1993. Págs. 43-54.

(5) SKJOLD, S.: Early warning system alerts Norwegians to a dam's visual impact. Landscape Architecture. 57. 1967. Págs. 185-187.

(6) RODENAS, M., SANCHO ROYO, F. Y GONZÁLEZ BERNÁLDEZ, F.: Structure of landscape preferences: a study based on large dams viewed in their landscape setting. Lanscape planning 2. 1975. Págs. 159-178.
(7) CAÑASGUERRERO, I.: Introducción al paisaje. $1^{\text {a }}$ edición Unicopia, Lugo. 1995.

(8) CAÑAS GUERRERO, I.: Valoración del paisaje. $1^{\text {a }}$ edición. Unicopia, Lugo. 1995.

(9) CAÑAS GUERRERO, I.: García García, A.I.: Principales variables que inciden en la integración de las construcciones agrarias en el paisaje. Informes de la Construcción. Vol. 46-Nº 433, septiembre/octubre, 1994. Págs. 47-55.

(10) USDA Forest Service: National forest landscape management. Agriculture handbook number 462. U.S. Government Printing Office. Washington. 1974.

(11) USDA Soil Conservation Service: Procedures to establish priorities in landscape architecture. U.S. Government Printing Office. Washington. 1978.

(12) USDI Bureau of Land Management: Visual resource management. Government Printing Office. Washington. 1980. 